\title{
LEGALIDADE DA SOCIEDADE EM CONTA DE PARTICIPAÇÃO COMO TÉCNICA DE CAPTAÇÃO DE RECURSOS PARA EXECUÇÃO DE CONTRATOS DE PARCERIA COM A ADMINISTRAÇÃO PÚBLICA
}

\author{
LEGALITY OF THE PARTICIPATION ACCOUNT AS A FUNDRAISING \\ TECHNIQUE FOR THE EXECUTION OF PARTNERSHIP AGREEMENTS WITH
}

THE PUBLIC ADMINISTRATION

Bernardo Strobel Guimarães ${ }^{1}$

Caio Augusto Nazario de Souza ${ }^{2}$

\begin{abstract}
RESUMO: O artigo discute a possibilidade da constituição de sociedade em conta de participação pelo particular como forma de captar recursos para executar contratos de concessão. Após análises acerca da possibilidade ou não de mudanças subjetivas nos contratos administrativos, bem como sobre o regime legal da sociedade em conta de participação, a conclusão é a de que a sua simples constituição por parte do licitante é indiferente para o Poder Concedente pois não altera a relação havida entre este e o concessionário. A utilização desse meio de captação de recursos é, em regra, irrelevante para o Poder Concedente, que sequer precisa ser comunicado de operações dessa natureza, pois elas não atingem a execução do contrato. Isso não quer dizer, porém, que a utilização dessa técnica pode levar a modificações indiretas no poder de controle da concessionária ou servir de burla para contornar a aplicação de sanções.
\end{abstract}

Palavras-chave: Sociedade em conta de participação; concessões públicas.

ABSTRACT: The article discuss the legality of the constitution of a company in

\footnotetext{
${ }^{1}$ Professor Adjunto de Direito Administrativo e Econômico da Pontifícia Universidade Católica do Paraná. Professor Substituto de Direito Econômico na Universidade Federal do Paraná. Doutor em Direito do Estado pela Universidade de São Paulo (2011). Mestre em Direito do Estado pela Universidade de São Paulo (2007). Especialista em Direito Tributário pela Pontifícia Universidade Católica do Paraná - PUC/PR (2002). Especialista em Direito Econômico pela Sociedade Brasileira de Direito Público (2002). MBA em Gestão Estratégica de Empresas pela ISAE/FGV (2013). Bacharel em Direito pela Pontifícia Universidade Católica do Paraná - PUC/PR (2002). E-mail: academico@strobelguimaraes.com. Currículo Lattes: http://lattes.cnpq.br/0678600050387547. ORCID: https://orcid.org/0000-0003-2826-7607.

${ }^{2}$ Graduado em Direito pela Pontifícia Universidade Católica do Paraná, alumnus especial na disciplina de Direito Econômico pela UFPR e cursa LLM. em Direito Empresarial pela FGV/RJ, possui experiência na área de Direito Administrativo desde 2012. É membro do Grupo de Estudos de Direito Processual Civil da PUC/PR. Possui diversas publicações bibliográficas e artigos envolvendo infraestrutura. Membro da Comissão de Infraestrutura e Desenvolvimento Sustentável da OAB/PR. Advogado é sócio do escritório Strobel Guimarães Sociedade de Advogados. E-mail: caio@strobelguimaraes.com. Currículo Lattes: http://lattes.cnpq.br/9796809615719092. ORCID: https://orcid.org/0000-0002-9026-0097.
} 
participation by the particular as a way of raising funds to execute concession contracts. After analyzing the possibility or not of subjective changes in administrative contracts, as well as the legal regime of the company in the participation account, the conclusion is that the simple constitution of a participation account company is indifferent to the Granting Authority because it doesn't change the relationship between him and the concessionaire. The use of this means of raising funds is, as a rule, irrelevant to the Granting Authority, which does not even need to be communicated about operations of this nature, as they do not reach the execution of the contract. That doesn't mean, however, that the use of this technique can lead to indirect changes in the concessionaire's power of control or serve as a swindle to circumvent the application of sanctions.

Keywords: Participation account partnership; public concessions.

Sumário: 1. Introdução; 2. Contratos administrativos e mutabilidade subjetiva: a mudança como expressão legítima da autonomia do parceiro privado; 3. Limites à competência para autorizar modificações subjetivas; 4 . O regime legal da sociedade em conta de participação; 5. A utilização da conta de participação nos contratos de parceria: possibilidades e limites; 6. Considerações finais; 7. Referências.

\section{INTRODUÇÃO}

O Brasil precisa se desenvolver. E para isso é necessário investir em infraestrutura. Uma das estratégicas para tanto é se valer de contratos de parceria. ${ }^{3}$ Por meio deles, particulares se obrigam a atuar em nome do Estado, prestando atividades econômicas reservadas ao Poder Público, financiando o empreendimento e assumindo os riscos correlatos.

A adoção de modelos dessa natureza exige que se calibrem interesses potencialmente dissonantes. De um lado, a Administração Pública deve ser dotada de competências que garantam a boa prestação dessas atividades que, afinal de contas, são públicas. É, portanto, natural que haja um certo poder de direcionar a execução do contrato, impondo-se esses desígnios aos particulares, que têm sua posição funcionalizada em vista do interesse público.

Todavia, isto não torna o particular um servo da Administração. Pelo contrário, é da essência dos contratos de parceria que o particular encarregado de executar o contrato seja capaz de gerir o empreendimento, assumindo os riscos de suas escolhas. Para tanto, deve

\footnotetext{
${ }^{3} \mathrm{O}$ termo contrato de parceria se refere aqui a qualquer contrato celebrado entre a Administração e particulares que transfira a esses a gestão empresarial de ativos ou atividades públicas. Em regra, são contatos de concessão (comum, patrocinada ou administrativa).
} 
existir liberdade para organizar os fatores necessários à prestação da atividade. O resultado econômico final do empreendimento deve refletir os acertos e erros do particular, o que remete à tradicional expressão de que esses contratos se exercem por "conta e risco" do particular. Em termos simples: é da essência do modelo de concessão que haja autonomia do particular, e esse núcleo deve ser garantido. Do contrário, perde-se a própria essência desses contratos.

Isto significa que contratos de parceria pressupõem que o particular tenha liberdade para organizar a forma de exploração do empreendimento. Sem isto, o particular se torna um prestador de serviços ordinário, que não aporta ao empreendimento sua experiência para o desenvolvimento da atividade. Se assim for, trata-se de arranjo diverso, e não de uma parceria. Essa liberdade é funcionalizada (e não anulada) em decorrência do atendimento dos objetivos públicos pressupostos pelo contrato. ${ }^{4}$

Nos contratos de parceria, é necessário equacionar esse dilema entre comando e liberdade. Definir esse suum cuique tribuere é essencial para compreender a lógica destes vínculos. Em termos abstratos, a resposta é simples: a intrusão da Administração sobre a autonomia empresarial está limitada aos aspectos necessários à fiel execução do contrato, que tem por objetivo final realizar concretamente interesses públicos. O problema é que a simplicidade que se encontra na abstração deve ser testada contra a realidade. Eis aí o nó górdio dessas questões, já que a realidade dificilmente consegue ser domada pelas previsões feitas em abstrato. A execução dos contratos coloca traz dilemas que escapam às predições legais.

Todavia, não raro, a interpretação que é feita desses temas despreza a proteção da autonomia privada, no altar da metafísica de um interesse público lido como voluntarismo da Administração. Isto implica em uma funcionalização desmedida da posição do particular que vai no sentido diametralmente oposto aos pressupostos dos contratos de parceria.

O sucesso do empreendimento depende da liberdade de gestão do particular. E é o sucesso do empreendimento o objetivo a ser atingido, na exata medida em que é isso que

\footnotetext{
${ }^{4}$ Para aprofundar esse tema, ver GUIMARÃES, Bernardo Strobel. Os contratos de concessão como técnica de efetivação de benefícios sociais e os reflexos no seu equilíbrio econômico-financeiro. Experiências práticas em concessões e PPP. Estudos em homenagem aos 25 anos da Lei de Concessões, vol. II, São Paulo: Quartier Latin, 2021, p. 343 e ss.
} 
gera os benefícios sociais esperados, que constituem a própria causa de uma atividade ser pública. Em outras palavras: a Administração age para que o contrato gere benefícios, de forma que qualquer desencaminhamento objetivo entre o melhor para o contrato e a vontade da Administração configura desvio de finalidade.

Em suma, há uma reserva de autonomia inerente à atuação do particular que deve ser a mais ampla possível diante do caso concreto. Restrições a essa autonomia devem ser justificadas, e não apenas retoricamente, até mesmo porque o Poder Concedente não é superego da vida negocial do particular, mas sim o guardião do interesse público. E o interesse do Estado é que o contrato seja bem executado, o que implica respeitar a autonomia do particular que é conferida pelo contrato. Exatamente por isso as prerrogativas da Administração no que se refere à execução do contrato devem ser lidas com parcimônia. Elas não configuram cartas de super-trunfo a serem lançadas a esmo contra o particular, variando ao sabor de conveniências políticas.

É da essência dos contratos de parceria que o particular possa organizar sua atividade empresarial de modo autônomo. Esta capacidade de tomar e administrar riscos está na própria base desses instrumentos de transferência de atividades públicas aos particulares. Tanto maior os riscos do particular quanto maior for a sua liberdade de organizar os fatores inerentes à execução do contrato.

Tais lembranças vêm a calhar para que se possa examinar o tema de investigação aqui proposto que consiste em avaliar se é legítimo àqueles que celebram contratos de parceria com a Administração constituir sociedades em conta de participação com vistas a financiar o empreendimento ou se, pelo contrário, tal hipótese dependeria de estar prevista e ser autorizada pelo Poder Público?

O tema diz respeito a temas relevantes para a compreensão dos contratos de parceria e como eles devem ser geridos, bem como diz respeito à maneira pela qual o particular obterá recursos para fins de executar os contratos de parceria, o que impacta diretamente na rentabilidade desses empreendimentos. Um dos pontos que tradicionalmente se coloca ao particular diz respeito ao financiamento do empreendimento, correndo à sua conta obter os recursos necessários para que o empreendimento seja viabilizado.

O ponto a ser destacado dessa introdução é que discutir a possibilidade ou não da 
utilização da sociedade em conta de participação remete à discussão acerca de qual é o espaço de autonomia para o empreendedor financiar o projeto que deverá executar em substituição ao Estado.

Por fim, diga-se que quanto aos objetivos, a pesquisa aqui apresentada é exploratória, visando proporcionar maior familiaridade com o problema investigado, explicitá-lo e construir hipóteses sobre as possibilidade e limites da constituição de sociedade de conta de participação por parte do particular quando contratado pelo Estado. Ademais, a abordagem é eminentemente qualitativa e se utilizou como metodologia o levantamento bibliográfico sobre o tema.

\section{CONTRATOS ADMINISTRATIVOS E MUTABILIDADE SUBJETIVA: A MUDANÇA COMO EXPRESSÃO LEGÍTIMA DA AUTONOMIA DO PARCEIRO PRIVADO}

Antes de se aprofundar no assunto e nas regras específicas que regem a sociedade em conta de participação, importa fixar algumas premissas teóricas acerca de dois temas centrais à compreensão do problema, tal como ele é encarado usualmente. Em regra, a utilização da sociedade em conta de participação é remetida a questões relativas à composição subjetiva do concessionário, tema esse que por si só merece esclarecimentos.

Deste modo é necessário examinar ainda que em suas linhas gerais o regime da mutação subjetiva dos contratos administrativos e qual o papel da Administração no controle dessas modificações e que se avalie a própria natureza jurídica da sociedade em conta de participação, de modo a responder se elas implicam ou não mutações subjetivas.

No regime dos contratos de parceria, um dos pontos nos quais há limitação da autonomia é a conformação subjetiva daquele a quem incumbe executar as prestações públicas. Compreender o fundamento disto e qual é o papel da Administração nesse processo é relevante para o tema a ser enfrentado aqui.

A questão é saber se os fundamentos que autorizam à Administração controlar a estrutura subjetiva do particular se aplicam à constituição de sociedade em conta de participação por parte do concessionário. Para tanto é necessário compreender o fundamento subjacente ao controle da composição societária do empreendimento. 
A celebração de contratos com a Administração Pública, em regra, depende de um procedimento objetivo de escolha cujo objeto é selecionar a melhor proposta, isto é, aquela que apresenta maiores vantagens de acordo com o previsto no edital. No que se refere aos contratos de tipo concessionário, a exigência de licitação é reforçada pelo próprio art. 175 da Constituição.

Isto visa não só garantir a igualdade de acesso às oportunidades econômicas geradas pelo Estado (isonomia), mas também assegurar que o escolhido tenha, objetivamente, condições de executar o objeto, o que se verifica na fase de habilitação. A competição é fundamental, precisamente, porque muitas vezes é aí que se transferem vantagens aos usuários, pois muitos serviços públicos não admitem competição.

Tem-se, então, que o procedimento de contratação se depara com uma etapa em que se analisa precisamente a capacidade de o particular executar o objeto do contrato que pretende celebrar com a Administração. Há, antes da assinatura do contrato por parte do licitante vencedor, uma etapa de habilitação, que varia em função do objeto do contrato. Diferentes contratos podem ensejar diferentes modos de habilitação (p. ex. a compra de imóvel exige depósito de parcela do valor, cf. art. 18 da Lei no 8.666/1993, que não possui correspondência na Lei $\left.\mathrm{n}^{\mathrm{o}} 14.133 / 2021\right){ }^{5}$

A complexidade da habilitação está diretamente correlacionada à complexidade do contrato administrativo. Em contratos de parceria, a regra é que a licitação se dê na modalidade de concorrência, em que existe uma etapa autônoma para aferir se o particular reúne as condições reputadas necessárias à execução do objeto. Em termos simples, a habilitação consiste em uma etapa do procedimento de escolha e se destina a demonstrar, objetivamente, que o contratado tem, ao menos em abstrato, condições para executar adequadamente suas obrigações. Só poderão contratar com a Administração os que demonstrem atender as condições definidas pela Administração, que deve observar os requisitos legais e se limitar a aferir circunstâncias que, realmente, digam com a capacidade

\footnotetext{
${ }^{5}$ Sempre que aqui se fizer referência a algum artigo da Lei $n^{\circ}$ 8.666/1993 também será indicado o artigo correspondente na Nova Lei de Licitações, caso existente, e vice-versa. E isso porque, nos termos do art. 193, inc. II, da Lei 14.133/2021, durante o prazo de dois anos a contar da sua publicação oficial suas disposições vigerão concomitantemente junto às normas previstas na antiga Lei, salvo no que toca às previsões penais, que foram revogadas de imediato.
} 
de executar as obrigações contratuais. Nos dizeres de Marçal Justen Filho (2021, p. 773), a habilitação "[...] consiste no conjunto ordenado de atos a apurar a idoneidade e a capacitação de sujeito para contratar com a Administração Pública". É nessa fase que a Administração decide "[...] sobre a presença das condições do direito de licitar".

Nessa linha, como a escolha do parceiro realizada pela Administração deriva de elementos mensurados no momento da escolha do particular, tem-se que em regra não pode haver a alteração deles durante a execução do contrato. Daí, exigir-se que as condições da habilitação sejam mantidas no curso da execução do contrato, inclusive no que se refere às características subjetivas do particular. Em suma: o elemento subjetivo do contratado é relevante pois é nele que reside a comprovação dos requisitos necessários para a execução do contrato.

Há os que equiparam essa peculiaridade como equivalendo ao caráter personalíssimo dos contratos privados. Daí ser comum a referência de que o contrato administrativo tem a característica de ser intuitu personae. Contudo, a expressão é manifestamente mal utilizada nos contratos administrativos.

No direito privado, contratos intuitu personae são aqueles em que a escolha do contratado se deu por conta dos seus elementos personalíssimos, que vinculam o contratado de modo indelével à satisfação da obrigação. Como ensina Orlando Gomes (2007, p. 97), “O contrato é intuitu personae quando a consideração da pessoa de um dos contratantes é, para o outro, o elemento determinante de sua conclusão".

Nos contratos administrativos, contudo, a lógica é diametralmente oposta. Neles, não são as características inerentes ao sujeito que importam para sua escolha. É exatamente o contrário: a escolha se dá por critérios objetivos, e não subjetivos. ${ }^{6}$ Ou seja, a contratação precedida de licitação se dá em função de critérios que podem ser, objetivamente, mensurados.

Tanto é que onde não houver disputa objetiva tem-se a inexigibilidade de licitação, nos termos do art. 25 da Lei $n^{\circ} 8.666 / 1993$, atual art. 74 da Lei $n^{\circ} 14.133 / 2021$. É a proposta

\footnotetext{
${ }^{6}$ Para um exame aprofundado da questão sobre a mutação subjetiva nos contratos administrativos, ver JUSTEN FILHO, Marçal. Considerações acerca da Modificação Subjetiva dos Contratos Administrativos, Fórum de Contratação e Gestão Pública - FCG., Belo Horizonte, ano 4, n. 41, maio 2005.
} 
o elemento vinculante, e não o particular que a executa. Como exemplo disto, tem-se que se houver inexecução do contrato, respeitados os requisitos da lei, pode ser chamado outro contratado para executar a parcela inadimplida, desde que se vincule à proposta vencedora (art. 24, inc. XI da Lei $n^{\circ} 8.666 / 1993$, atual $\S 7^{\circ}$ do art. 89 da Lei $n^{\circ} 14.133 / 2021$ ). Isso se dá exatamente pois o que vincula as partes é a proposta, e não quem há de executá-la.

Em suma, o que é objeto de seleção pela Administração é a melhor proposta, definida em termos objetivos e não uma pessoa específica em face de suas características pessoais. Como explica Rafael Véras de Freitas (2016, p. 71), “[...] por meio desse procedimento, o Poder Público tem por objetivo selecionar a 'melhor proposta', e não o 'melhor contratado'. Ou seja, o referido procedimento visa a selecionar um parâmetro qualitativo de bem ou do serviço, e não um contratado em especial.” É esse parâmetro que deve ser preservado, e não qualquer vinculação pessoal do agente. Ou, dizendo de outro modo, como o interesse primordial do Estado não está vinculado às características subjetivas do licitante vencedor, mas sim à contratação de licitante idôneo que apresentar a proposta mais vantajosa e que se comprovar capaz de executá-la fielmente, não há motivos para se impedir de antemão toda e qualquer modificação contratual subjetiva.

Embora tanto os contratos administrativos quanto contratos intuitu personae impliquem restrições no que toca à modificação subjetiva do contratante, as causas que levam a tal efeito são substancialmente distintas, já que do ponto de vista dos contratos administrativos não há uma afetação subjetiva do particular à execução contratual. A vinculação subjetiva é derivada da objetiva. E não um fim em si mesmo como se dá em âmbito privado. O efeito disto é que a análise sobre a alteração subjetiva para a Administração é objetiva e segue a mesma racionalidade estipulada no momento da escolha. Em suma, não há espaços para casuísmos e decisões discricionárias. Neste contexto é que surge o dever de o particular preservar as condições inerentes à escolha realizada por meio da licitação; a alteração subjetiva é legítima se as condições objetivas avaliadas forem preservadas.

Como se vê, a legislação não veda a alteração subjetiva, mas sim impõe procedimentos a serem observados. Nada obstante a tradição de se enxergar nestes contratos 
a natureza intuitu personae, fato é que a Lei admite a modificação. ${ }^{7}$ O que a Lei de Licitações veda, seja a antiga ou a nova, não é toda e qualquer espécie de modificação subjetiva, mas apenas as modificações societárias, finalísticas ou estruturais da empresa que de alguma forma restrinjam a sua capacidade de concluir o contrato da forma originalmente pactuada (art. 137, inc. III, da Lei ${ }^{\circ}$ 14.133/2021 e art. 78, inc. XI, da Lei no 8.666/93).

Logo, as restrições que surgem ao exercício da autonomia privada que derivam dos contratos administrativos têm por pressuposto a preservação das condições objetivas de contratação. O reverso disto é que a competência de a Administração controlar modificações que impactem sobre seus contratados tem finalidade certa: assegurar que não haja degradação do nível de exigências estipulado por ocasião da licitação.

Do ponto de vista normativo quanto aos contratos de parceria, a Lei de Concessões se ocupa do tema indicando ainda que alterações que impliquem a modificação do controle do concessionário devem ser aprovadas pela Administração. A inobservância dessa formalidade conduz à declaração da caducidade do contrato. Nesse sentido, dispõe o art. 27 da Lei $n^{\circ} 8.987 / 1995$.

Como se percebe, ao prever a possibilidade de haver a modificação é de se perceber que está a se constituir um espaço de autonomia em favor do particular. Obedecidas as exigências referentes à habilitação e, claro, em inexistindo risco objetivo de dano à Administração pública, notadamente no que toca à execução do contrato, o particular tem o direito subjetivo de promover mudanças subjetivas. Circunstância essa, por vezes, necessária à própria execução do contrato, especialmente tendo em vista o longo prazo pelo qual vigem os contratos de parceria. O que é importante perceber aqui é que as mudanças subjetivas em contratos de longa duração são instrumentos de financiamento do empreendimento. A atração de novos atores que investirão no negócio é, muitas vezes, uma ferramenta essencial à saúde financeira do concessionário, que não deve ser tolhida por razões caprichosas.

A mutação nada constitui de excêntrico. Isto porque durante a vida do contrato administrativo podem surgir situações que levem à conveniência (ou mesmo à necessidade)

\footnotetext{
${ }^{7}$ A afirmação é tradicional em nossa doutrina. Para uma crítica a essa concepção, especialmente nos contratos de concessão, consultar: KUBRUSLY, Cláudia Tosin. Modificações Subjetivas nos Contratos de Concessão (Comentários a acórdão do STJ), Revista de Direito Público da Economia - RDPE, Belo Horizonte, ano 2, n. 6, abr. / jun. 2004.
} 
de mudanças que impactam na composição subjetiva do contratado. A mutabilidade desses contratos não se limita às condições pelas quais o serviço é prestado. Ela muitas vezes se projeta sobre a própria pessoa do particular.

Como sabido, a vida negocial por vezes traz a necessidade de haver mudanças na personalidade jurídica das empresas. Processos de transformação societária (fusões, cisões, incorporações) e mudanças na composição acionária são exemplos corriqueiros disto. Em regra, tais transformações são manifestação legítima da autonomia negocial (que não é eliminada pelo fato de o particular ser contratado pela Administração).

Como registra a doutrina, a alteração subjetiva do concessionário não só é legal, mas constitui materialização de uma característica fundamental do regime jurídico dessa modalidade contratual, que é a autonomia de gestão (SUNFELD, 2015, p. 195). Isto é especialmente verdade nos contratos de longo prazo (como os contratos de concessão em sentido amplo). No longo prazo, é comum que reestruturações societárias venham a acontecer, mudança nos grupos de acionistas, etc. Num mercado maduro de investimentos há comumente negociações entre agentes econômicos que atuam no setor de infraestrutura. Mesmo os financiamentos obtidos junto a instituições públicas muitas vezes são viabilizados por meio de participações societárias, como ocorre por exemplo com o braço de investimentos do Banco Nacional do Desenvolvimento Econômico e Social - BNDES.

Logo, a questão que se coloca é como compatibilizar a mutabilidade com a proteção da Administração. De um lado, há a necessidade de se preservar a autonomia privada. De outro, é legítimo que a Administração venha a ver preservado o nível de segurança exigido quando da escolha do contratado. A solução deste dilema inevitavelmente passa por reafirmar o sentido e o alcance das prerrogativas da Administração relativas às alterações subjetivas.

\section{LIMITES À COMPETÊNCIA PARA AUTORIZAR MODIFICAÇÕES SUBJETIVAS}

Posta a questão da mutação como expressão legítima da autonomia do parceiro privado, conclui-se que o controle das alterações contratuais por parte da Administração somente pode ser exercido nos limites necessários para garantir que o contrato seja 
corretamente executado. Essa é a solução do nosso direito positivo no que se refere às concessões. $\mathrm{O}$ art. $27, \S 1^{\circ}$, I da Lei de Concessões indica que a análise a ser levada a efeito pelo Poder Concedente deve avaliar se persistem íntegras as condições subjetivas denotativas da capacidade de executar o contrato.

Nesse sentido, note-se que as restrições à mutabilidade, na exata medida em que limitam um atributo inerente à livre organização empresarial, devem ser justificadas de maneira específica e se sujeitam à proporcionalidade, regra essa que vale mesmo para os editais e contratos, que só podem promover restrições que digam respeito à preservação das condições de habilitação. Restrições que vão além da boa execução do contrato são censuráveis, pois constituem restrições desproporcionais. A intensidade da restrição é limitada por esse objetivo. Dito de outro modo: o limite do controle é a análise objetiva relativa às condições de execução do contrato.

Logo, a interpretação das cláusulas que implicam restrição à livre organização empresarial deve observar tais diretrizes, sob pena de se limitar indevidamente a autonomia do particular. Mesmo os que afirmam existir caráter pessoal na execução dos contatos de concessão entendem que as competências administrativas são limitadas, não sendo passíveis de serem exercidas livremente. Em nenhuma circunstância se admite que a Administração negue por motivos caprichosos modificações no que se refere à personalidade jurídica do contratado.

Sobre o tema, André de Laubadère, que alude ao caráter intuitu personae dos contratos administrativos, destacava que "A administração não dispõe de um poder discricionário para recusar a aprovação da cessão ou sub-contratação solicitadas. Uma tal rejeição não pode ser fundada senão sobre 'motivos tirados da incapacidade técnica ou financeira do concessionário proposto"”. (LAUBADÈRE, 1956, p. 111, trad. livre). Esse entendimento é acompanhado pelo Conselho de Estado desde a década de 1940. Como se vê, o poder de controlar as mutações subjetivas jamais foi visto como dando margem a caprichos e casuísmos. Em sendo preservadas as condições de escolha, é dever aprovar as modificações - e não faculdade.

A competência para analisar as modificações está restrita à análise das condições inerentes à execução do contrato. Somente a incapacidade técnica ou financeira, 
demonstrada objetivamente, pode servir de base para uma negativa dessa ordem. Eis o limite das prerrogativas outorgadas à Administração e o fundamento de validade das normas contratuais acerca do tema. No mesmo sentido, registra-se a opinião de Marçal Justen Filho (2021, p. 1460), para quem a alteração da estrutura societária do licitante vencedor, por si só, não é capaz de justificar a extinção do contrato. Em qualquer caso, é condição de possibilidade para a extinção a comprovação, por parte da Administração Pública, de que a modificação em questão "[...] torna inviável a execução do contrato. Têm de existir elementos concretos evidenciadores de prejuízo ou que autorizem a presunção de que, sob a nova roupagem, a contratante não executará corretamente suas prestações”.

Todas essas premissas convergem para uma conclusão clara: as competências para analisar modificações subjetivas quanto à pessoa do contratante têm por fundamento e limite a análise da capacidade de executar o objeto. Fora disso, a alteração é indiferente para a Administração que deve aceitá-la, pois não há motivo válido para limitar a autonomia do contratado na gestão do contrato. Qualquer coisa que vá além disso implica desvio de finalidade e abuso de poder. A Administração não é superego da vida negocial do concessionário; mas apenas fiscal da boa execução do contrato.

Como será gerida a concessão é assunto que diz respeito à autonomia inerente ao concessionário, que administra os riscos inerentes ao seu negócio da maneira mais livre possível. Retomando a expressão tradicional, a concessão se explora por "conta e risco" do particular. E isto significa reconhecer a capacidade de organizar os fatores econômicos necessários à boa execução do contrato.

Em síntese: alterações subjetivas do licitante só são relevantes para a Administração se e quando elas impactarem na execução do contrato. Alterações que não afetem a execução dos contratos são irrelevantes. A elas, o Poder Concedente não pode opor resistência direta ou indireta; pois são exercício legítimo da autonomia empresarial das concessionárias.

Mais do que isso, o controle da Administração Pública sobre a pessoa do contratado diz respeito apenas à demonstração objetiva da capacidade de executar o contrato nos termos pactuados. Tudo que desborde disso é manifestamente ilegal. A Administração não tem qualquer interesse na pessoa que executa o contrato, ela tem interesse na preservação objetiva da capacidade aferida para sua execução. Esse é o fundamento último de todas as 
competências administrativas que dizem respeito à avaliação subjetiva do particular contratado.

\section{O REGIME LEGAL DA SOCIEDADE EM CONTA DE PARTICIPAÇÃO}

Esclarecidas as principais ideias que justificam o controle da Administração sobre a personalidade dos sujeitos por ela contatados, pode-se analisar o regime normativo das sociedades em conta de participação, objeto imediato das atenções desse texto.

Compreender o regime jurídico relativo à sociedade em conta de participação aqui é fundamental. Isso porque as regras que a disciplinam são peculiares, afastando-as de outras sociedades personificadas. As peculiaridades da conta de participação são especialmente interessantes quando se pensa na sua utilização nos contratos administrativos.

Em termos simples, sociedades em conta de participação são associações não personificadas cuja característica elementar é que toda atuação empresarial é desenvolvida pelo chamado sócio ostensivo, que conduzirá em nome próprio e sem qualquer limitação em suas responsabilidades os negócios da sociedade.

As relações entre os sócios da conta de participação são puramente internas, não se projetando externamente nas relações desenvolvidas pelo sócio ostensivo. Em termos diretos, quem atua concretamente é o sócio ostensivo, os demais apenas têm relações internas com ele, não havendo projeção externa desses vínculos. Como explica Fábio Ulhoa Coelho (2006, p. 447):

\footnotetext{
Um empreendedor (chamado sócio ostensivo) associa-se a investidores (os sócios participantes), para a exploração de uma atividade econômica. O primeiro realiza todos os negócios ligados à atividade, em seu próprio nome, respondendo por eles de forma pessoal e ilimitada. Os agentes econômicos que entabulam negociações com o sócio ostensivo não precisam saber, necessariamente, que a atividade em questão é explorada sob a forma de uma conta de participação.
}

Trata-se, portanto, de uma modalidade especialmente vocacionada à segregação de riscos empresariais, em que um dos partícipes assume todo o risco empresarial do negócio, competindo aos demais somente participar dos resultados nos termos definidos no contrato que institui a conta de participação. Isso, contudo, não altera o fato de que o sócio ostensivo permanece com sua atuação íntegra, não havendo qualquer efeito externo derivado da conta 
de participação.

A regulação originária dessas sociedades é antiga. O Código Comercial de 1850 (cf. arts. 325 a 328), disciplinava o tema em termos bastante similares aos que atualmente se encontram em nosso direito positivo. Atualmente, é o Código Civil que trata do tema nos arts. 991 a 996. Desde a origem, o modelo normativo se caracteriza por essa nota de segregação entre relações internas e externas.

A análise do regime normativo vigente permite destacar as principais características deste contrato peculiar:

- $\quad$ Cuida-se de sociedade que não tem capital social ou nome próprios, pois não tem personalidade (art. 993 do CC);

- $\quad$ exercício das atividades compete exclusivamente ao sócio ostensivo, que age em nome próprio em todas as relações em que vier a participar, ficando os sócios participantes alheios a tais atos (art. 991 do CC);

- A constituição da sociedade independe de quaisquer formalidades e dispensa registro (arts. 992 e 993 do CC);

- As relações entre os sócios constituem-se em patrimônio especial, sendo que tal relação se limita apenas aos seus participantes, não gerando quaisquer efeitos sobre terceiros (art. 994, caput e $\S 1^{\circ}$ ).

Essas características denotam que a conta de participação é bastante distinta das demais modalidades societárias admitidas em nosso Direito. Trata-se de modelo sui generis, cujas peculiaridades devem ser levadas em consideração. Aliás, tantas são as peculiaridades dessa modalidade que grande parte da doutrina nem sequer a considera, propriamente, uma sociedade, mas antes um contrato de investimento. ${ }^{8}$ Para José Edwaldo Tavares Borba (2012, p. 113-115), por exemplo, a natureza da sociedade em conta de participação é contratual porque ela carece de dois elementos indispensáveis para que se possa falar em uma

\footnotetext{
${ }^{8}$ Para uma resenha das opiniões acerca do tema e das dificuldades conceituais envolvidas consultar: ACETI JR., Luiz Carlos e REIS, Maria Flávia Curtolo. Sociedade em Conta de Participação, Revista dos Tribunais $\mathrm{n}^{\mathrm{o}}$ 794, dez/2001, p. 727-745.
} 
sociedade, quais sejam, patrimônio próprio e personalidade jurídica. Importante mencionar, porém, ainda que brevemente, que esse entendimento não é pacífico. José Gabriel Assis de Almeida (1989, p. 31) é um dos autores que advogam pela natureza societária da sociedade em conta de participação, sustentando para tanto que "[...] face às disposições do direito positivo brasileiro, não parece haver motivo para recusar à Conta de Participação o caráter de sociedade, já que ela preenche, com perfeição, todos os requisitos legais.”

Essa discussão, porém, é irrelevante para o exame da questão aqui proposta, motivo pelo qual não será objeto de maiores considerações. O que importa destacar nesse primeiro momento é que as peculiaridades da sociedade em conta de participação trazem consequências importantes no que se refere a parcerias que envolvem a exploração de contratos administrativos. Em especial, a responsabilidade integral do sócio ostensivo e a ausência de capital próprio trazem efeitos relevantes para fins de definir sua potencial utilização em contratos públicos.

Como anotado acima, compete exclusivamente ao sócio ostensivo dirigir o negócio, atuando em nome próprio e sendo integralmente responsável perante terceiros por todas as obrigações assumidas em nome da sociedade. A existência ou não de uma conta de participação em nada altera o dever de o sócio ostensivo adimplir fielmente todas as obrigações que vier a constituir. Como ensina Marlon Tomazette (2019, p. 331):

\footnotetext{
o sócio ostensivo, que pode ser um empresário individual ou uma sociedade, é aquele que exercerá a atividade em seu próprio nome, vinculando-se e assumindo toda a responsabilidade perante terceiros. A sociedade em conta de participação não firmará contratos. Quem firmará os contratos necessários para o exercício da atividade é o sócio ostensivo, usando tão somente seu próprio crédito, seu próprio nome. Quando ele age, não age como um administrador de uma sociedade, mas como um empresário, seja ele individual, seja uma sociedade.
}

Como se nota, a constituição de conta de participação não altera ou flexibiliza em nada as relações jurídicas celebradas pelo sócio ostensivo. É o sócio ostensivo que permanece obrigado face a todos os demais sujeitos, sendo a relação entre este e os demais sócios da conta de participação incapaz de gerar efeitos externos.

Daí que a utilização da conta de participação cria dois feixes de relação que não se confundem. Um, envolvendo o sócio ostensivo, em que são centralizadas todas as obrigações 
negociais externas. Outro, que vincula apenas o sócio ostensivo com os demais sócios da conta de participação. Essa especial característica da conta de participação é afirmada pela jurisprudência, que reconhece que

na sociedade em conta de participação o sócio ostensivo é quem se obriga para com terceiros pelos resultados das transações e das obrigações sociais, realizadas ou empreendidas em decorrência da sociedade, nunca o sócio participante ou oculto que nem é conhecido dos terceiros nem com estes nada trata (REsp 192.603/SP, Rel. Ministro Barros Monteiro, DJ 01/07/2004, p. 197).

Como se vê, as relações entre os sócios da conta de participação em nada afetam as relações externas da empresa que ocupa a posição de sócia ostensiva. Em uma analogia simples: a conta de participação é uma sociedade meramente virtual, que não tem qualquer atuação tangível, dependendo do sócio ostensivo para praticar todo e qualquer ato negocial. É um espírito sem corpo, que depende de outra criatura para existir e agir. A conta de participação é relação que se estipula apenas entre o sócio ostensivo e os participantes, não gerando efeitos externos.

A par dessa característica, tem-se que a conta de participação não precisa ser publicizada, daí se dizer usualmente que se trata de uma sociedade "oculta". Note-se, contudo, que dizer que a sociedade em conta de participação é uma sociedade "oculta" deve ser visto com reservas, pois nisto nada há de irregular ou ilegal como pode sugerir uma leitura preliminar. Com efeito, o sigilo é perfeitamente próprio do mundo dos negócios, não havendo um dever implícito de full disclosure que se aplique aos agentes privados. A expressão "sociedade oculta" significa apenas que esta modalidade dispensa registro na Junta Comercial, como é a regra nas sociedades personificadas (CC, art. 985).

Além disto, a sociedade leva esta denominação também pelo fato de que o sócio participante, por não aparecer perante terceiros, não assume responsabilidades perante estes, cabendo, portanto, apenas ao sócio ostensivo a responsabilidade perante o público (CARVALHO DE MENDONÇA, 2001, p. 262). Aliás, a atuação direta do sócio oculto desnatura a própria essência da sociedade em conta de participação.

A publicização ou não da sociedade é elemento que em nada modifica sua natureza. Essa advertência é necessária apenas para que não se leia "oculto" como caracterizador de 
qualquer ilicitude ou ausência de transparência.

A sociedade em conta de participação é um instrumento salutar à organização da vida empresarial (tanto que é prevista no nosso ordenamento desde 1850) e que nada tem de anormal ou reprovável aos olhos da lei. Valer-se dela não implica necessariamente qualquer dissimulação ou ato censurável, mas sim a utilização legítima de uma modalidade típica de parceria entre empresas que existe no nosso ordenamento jurídico há mais de 170 anos.

\section{A UTILIZAÇÃO dA CONTA DE PARTICIPAÇÃO NOS CONTRATOS DE PARCERIA: POSSIBILIDADES E LIMITES}

Considerando as premissas expostas acima, conclui-se que a celebração de contrato de conta de participação por empresas que participam de negócios com a Administração é perfeitamente legal. A existência de ajustes dessa natureza é, por si só, indiferente à Administração. Os argumentos acima alinhavados convergem para que se conclua que a celebração de contrato de sociedade em conta de participação não caracteriza qualquer infringência da lei em abstrato.

Primeiro, porque a celebração de contrato em sociedade em conta de participação é indiferente para a Administração. Essa conclusão é decorrência lógica das premissas normativas expostas anteriormente. Isto porque a (i) Administração só deve controlar atos que impactem na capacidade de o contratado executar o contrato e (ii) na conta de participação o sócio ostensivo (que é o contratado) permanece integralmente responsável pelos compromissos que assume, logo a celebração de contrato dessa natureza é indiferente para a Administração.

O especial destaque dado ao fato de que a conta de participação não produz efeitos externos, bem como à limitação das competências administrativas relativas à mutação subjetiva se justifica aqui. Como visto, legalmente, a celebração de conta de participação não modifica em nada as obrigações do sócio ostensivo, que permanece integralmente obrigado à execução do contrato administrativo. Portanto, a conta de participação não alterará em nada a composição do capital social do sócio ostensivo e nem modificará a responsabilidade assumida integralmente por ele perante o Poder Concedente. Em termos simples: o Poder Concedente não será em nada afetado pela celebração do contrato de conta 
de participação, que, portanto, é para ele indiferente. Sobre a questão, anota Carlos Henrique de Mattos Sabino (2010, p. 193) que

[...] a priori, o fato da empresa licitante já participar de sociedade em conta de participação ou, após a contratação com o Poder Público, constituir tal espécie de ente jurídico não é proibido pela legislação, não viola as regras do edital de licitação ou do contrato administrativo, e, em nada prejudica o ente estatal. Os requisitos de habilitação técnica, jurídica e econômico-financeira sempre serão atendidos única e exclusivamente pela sócia ostensiva, a qual foi devidamente verificada pelo Poder Público.

Além disso, a sociedade em conta de participação não implica em envolvimento dos sócios no capital social do sócio ostensivo. A relação patrimonial que é constituída entre sócio ostensivo e sócios participantes é patrimônio especial, que não se confunde com o capital social do sócio ostensivo. Os sócios participantes não participarão do empreendimento público, sua relação se dá exclusivamente com o sócio ostensivo, não implicando qualquer modificação estrutural no que tange ao sócio ostensivo. Isso é decorrência direta do art. 994 do Código Civil, que indica que a conta de participação cria um patrimônio especial que vincula apenas os sócios da conta de participação $\left(\S 1^{\circ}\right)$. Esse patrimônio não se confunde com o capital social do sócio ostensivo, que permanece íntegro, gerando efeitos externos. Dito de outro modo, a sociedade que existe se limita a esse patrimônio especial, que não se confunde com o capital social da empresa licitante.

A relação é puramente interna (envolve apenas o sócio ostensivo e os sócios participantes) e restrita a esse quinhão. Os sócios participantes participam não da sociedade que se apresenta externamente, mas apenas da "conta de participação". Eles não são sócios da empresa que tem a competência para executar o contrato, estando limitados ao quinhão que constitui o patrimônio especial. É por isto que o art. 993 do CC destaca que o contrato social da conta de participação cria uma relação apenas entre seus sócios, que não afeta o capital social do sócio ostensivo. Tanto é assim que as contribuições pecuniárias eventualmente aportadas pelos sócios participantes não passam a integrar o capital social do sócio ostensivo, mas sim constituem patrimônio especial, segregado daquele (TOMAZETTE, 2019, p. 332). Os sócios participantes aportam recursos e têm direito de participar dos resultados, nos termos definidos no documento específico que os vincula ao 
sócio ostensivo. Nada além disso.

$\mathrm{Na}$ exata medida em que os sócios participantes não participarão do capital do empreendimento, deixa de se aplicar a regra geral de que o Poder Concedente deve analisar em caráter prévio a existência desses contratos. Desta forma, conclui-se que a celebração de contrato em conta de participação, nos termos em que ela é disciplinada no Código Civil, constitui operação que em nada interessa à Administração.

Em rigor, considerando o caráter interno das relações derivadas da conta de participação, tem-se que o melhor entendimento acerca do tema é que tal operação nem sequer precisaria ser levada a conhecimento do Poder Concedente, pois ela não traz qualquer mutação subjetiva que possa ser objeto da atenção da Administração. Aliás, como visto, é da essência da conta de participação que ela seja restrita aos sócios sem gerar efeitos externos, sendo que isso que justifica que a relação fique restrita apenas aos envolvidos nesse negócio específico.

A única ressalva que merece ser feita no que se refere à legalidade da utilização da sociedade em conta de participação diz respeito a casos em que além das cláusulas típicas desse contrato, criem-se outros compromissos entre as empresas, que impactam em temas sensíveis ao Poder Concedente. Nesse sentido, não se poderia utilizar a conta de participação como instrumento para dissimular transferências de controle ou implementar outros resultados que devem ser submetidos ao escrutínio da Administração. Como negócio atípico, pode ser que haja outras disposições nesses contratos que criem obrigações distintas daquelas previstas em Lei, como por exemplo exercício de poderes de controle por meio de direitos de voto e outras circunstâncias.

Portanto, existem claras exceções ao direito do licitante de se associar a terceiros para a execução do contrato. Nos dizeres de Marçal Justen Filho (2019, p. 1411), ${ }^{9}$ se configura uma exceção à liberdade de associação e, consequentemente, à constituição de sociedades

\footnotetext{
${ }^{9}$ A título de esclarecimento, vale dizer que aqui se utiliza a edição de 2019 pois os comentários do autor, que são pertinentes aos objetivos do artigo, foram dirigidos a um dispositivo que não se encontra presente na Lei $\mathrm{n}^{\mathrm{o}} 14.133 / 2021$, qual seja, o inc. VI do art. 78 da Lei $\mathrm{n}^{\circ}$ 8.666/1993, segundo o qual constituía motivo para a rescisão do contrato "a subcontratação total ou parcial do seu objeto, a associação do contratado com outrem, a cessão ou transferência, total ou parcial, bem como a fusão, cisão ou incorporação, não admitidas no edital e no contrato". De se notar, inclusive, que essa mudança reforça a tese exposta nesse artigo, já na Nova Lei a associação do contratado com outrem não mais configura uma das hipóteses de rescisão contratual.
} 
de conta de participação para fins de contratações públicas, a criação de sociedades de fato ou irregular, e isso porque em tais casos "A execução da prestação passaria ao encargo de terceiros (total ou parcialmente), o que não pode ser admitido especialmente porque a conduta do particular permanece oculta, não sendo lavada ao conhecimento da Administração". Importante notar, contudo, que nada disso decorre automaticamente da utilização da conta de participação. Respeitados os parâmetros legais, por si, a conta de participação é indiferente. O problema reside não na utilização da conta de participação, mas sim na previsão de outras obrigações que podem vir a contrariar regras legais ou contratuais.

Em outras palavras, a conta de participação não pode servir de instrumento para escamotear qualquer influência dos participantes na condução da Concessionária. A direção do negócio deve ser integralmente levada a efeito pela sócia ostensiva, que é quem foi selecionada pela Administração para gerir o empreendimento. Respeitados esses limites, a conta de participação é um meio de investir no empreendimento, mas não de outra relação que extrapole esse limite. E nesses casos, sua utilização é regular e lícita.

Nos casos em que a conta de participação puder impactar na direção da companhia ou produzir outro efeito que impacte os interesses da Administração (como por exemplo transferir materialmente a execução do contrato) ela deverá ser submetida ao Poder Concedente. Não por se tratar de conta de participação, mas por se tratar de negócio jurídico que afeta, potencialmente, o controle do particular.

A conta de participação constituída para captação de recursos não equivale aquela que implica, além disso, a existência de outras cláusulas que possam colidir com as disposições edital. Na exata medida em que a conta de participação ficar restrita ao modelo legal, sua utilização é indiferente à Administração. O que pode embaraçar sua utilização é a existência de disposições que impliquem na intrusão dos sócios participantes em dimensões que se sujeitam ao controle do Poder Concedente por se conectarem à própria execução do contrato.

Em linhas gerais, como o contrato de sociedade é atípico, deve se ter em mira que as suas regras não podem infringir prescrições do edital ou do contrato de concessão. Com efeito, o exercício da autonomia privada não se presta a dissimular o descumprimento de preceitos de ordem pública. Se é verdade que a utilização da conta de participação é lícita e 
possível, isso não implica que por meio dela se burlem os preceitos do contrato de concessão. Mas como dito, tudo isso não decorre da simples celebração do contrato de concessão. Respeitado o figurino típico desse negócio, ele é perfeitamente lícito.

\section{CONCLUSÕES}

Sintetizando as conclusões dos tópicos anteriores têm-se as seguintes ideias-chave.

(i) O sentido e o alcance das normas legais e contratuais que restringem a autonomia de o parceiro privado organizar livremente sua personalidade jurídica têm por finalidade assegurar que os critérios objetivos avaliados por ocasião da sua escolha na licitação sejam preservados, essa é a finalidade das competências administrativas neste tema;

(ii) A lei de concessões autoriza mudanças subjetivas, inclusive a alteração do poder de controle. O que ela exige é que haja comunicação preliminar, exatamente, para que se possa avaliar se persistem íntegros os elementos que foram considerados para fins de celebração do contrato. No contrato de sociedade em conta de participação todos os atos externos são imputados ao sócio ostensivo. Nestas sociedades, existe apenas uma relação interna e isolada entre o sócio ostensivo e os sócios participantes, que não se projeta externamente;

(iii) Na exata medida em que persiste íntegra a personalidade e as obrigações do sócio ostensivo, a celebração de contrato de constituição de sociedade em conta de participação não interessa à Administração;

(iv) Ainda que haja cláusula vedando qualquer alteração de capital, esta não se aplica à celebração de contrato de conta de participação, pois não há qualquer modificação do capital da sociedade que atua ostensivamente, há expressa segregação legal dos patrimônios entre os sócios, que não se confundem.

(v) De todo modo, não podem ser previstas livremente cláusulas que alterem indiretamente o controle, pois essas devem ser submetidas à aprovação preliminar do Poder Concedente, sempre em linha com os preceitos trazidos pelo Edital e pelo Contrato de Concessão.

(vi) Para fins do aqui exposto, há uma diferença entre sociedade de conta de participação constituída exclusivamente para fins de captação de recursos financeiros e sociedade em conta de participação na qual os sócios participantes estão envolvidos na execução do 
contrato. A primeira não só é legal como pode ser constituída e levada a efeito independentemente de conhecimento por parte da Administração, enquanto a segunda depende de autorização do Poder Público para existir porque implica em uma modificação subjetiva que impacta na execução do contrato.

(vii) A constituição de sociedade em conta de participação não se trata de uma carta branca à disposição do particular, sendo vedadas mudanças contratuais relativas a temas sensíveis à Administração Pública sem o conhecimento desta, como é o caso de alterações subjetivas ou na forma de execução do contrato. Em outras palavras, não é permitido ao licitante dissimular o descumprimento de preceitos de ordem pública, de forma que afirmar a legalidade e a viabilidade da utilização da conta de participação não implica em aceitar que por meio dela se burlem os preceitos do contrato de concessão ou as disposições legais aplicáveis.

\section{REFERÊNCIAS}

ACETI JR., Luiz Carlos e REIS, Maria Flávia Curtolo. Sociedade em Conta de Participação. Revista dos Tribunais, n. 794, dez/2001.

ALMEIDA, José Gabriel Assis de. A sociedade em conta de participação. Rio de Janeiro: Forense, 1989.

BORBA, José Edwaldo Tavares. Direito societário. Rio de Janeiro: Renovar, 2012.

BRASIL. Superior Tribunal de Justiça. Recurso Especial 192.603/SP. Relator: Ministro Barros Monteiro - Primeira Turma.

CARVALHO DE MENDONÇA, J. X. Tratado de direito comercial brasileiro. Atualizado por Ruymar de Lima Nucci. Campinas: Bookseller, 2001, v. 2, tomo 3.

COELHO, Fábio Ulhoa. Curso de Direito Comercial, v. 2. 9. ed. De acordo com a lei de falências. São Paulo: Saraiva, 2006.

FREITAS, Rafael Véras de. A subconcessão de serviço público. Revista Brasileira de Infraestrutura - RBINF. Belo Horizonte, ano 5, n. 10, p. 75-101, jul./dez. 2016.

GOMES, Orlando. Contratos. 26. ed., Rio de Janeiro: Forense, 2007.

GUIMARÃES, Bernardo Strobel. Os contratos de concessão como técnica de efetivação de benefícios sociais e os reflexos no seu equilíbrio econômico-financeiro. Experiências 
práticas em concessões e PPP, Estudos em homenagem aos 25 anos da Lei de Concessões, v. II, São Paulo: Quartier Latin, 2021.

JUSTEN FILHO, Marçal. Comentários à lei de licitações e contratos administrativos. 18 . ed. rev., atual e ampl. São Paulo: Thomsom Reuters Brasil, 2019.

JUSTEN FILHO, Marçal. Comentários à lei de licitações e contratações administrativas. São Paulo: Thomsom Reuters Brasil, 2021.

JUSTEN FILHO, Marçal. Considerações acerca da Modificação Subjetiva dos Contratos Administrativos. Fórum de Contratação e Gestão Pública - FCGP. Belo Horizonte, ano 4, n. 41, maio 2005.

KUBRUSLY, Cláudia Tosin. Modificações Subjetivas nos Contratos de Concessão (Comentários a acórdão do STJ). Revista de Direito Público da Economia - RDPE. Belo Horizonte, ano 2, n. 6, abr./jun. 2004.

LAUBADÈRE, André de. Traité théorique et pratique des contrats adinistratifs, t. 2, Paris: LGDJ, 1956.

SABINO, Carlos Henrique de Mattos. Sociedades em conta de participação e as licitações envolvendo concessões de transporte coletivo: riscos e possibilidades. A\&C - Revista de Direito Administrativo \& Constitucional. Belo Horizonte, ano 10, n. 39, jan./mar. 2010.

SUNFELD, Carlos Ari. Transferibilidade como elemento essencial da concessão. Pareceres - Direito administrativo contratual, v. 2, São Paulo: RT, 2015.

TOMAZETTE, Marlon. Curso de Direito Empresarial: teoria geral e direito societário, v. 1, 10. ed., São Paulo: Saraiva: 2019. 